\title{
Integrating Quantitative and Qualitative Approaches to Explore Absenteeism Attributed to Air Pollution and its Attributed Direct and Indirect Costs Among Private Sector Companies in Ulaanbaatar, Mongolia
}

\section{Mandukhai Ganbat}

Zaigal Research Institute

Nasantogtokh Erdenebileg

Zaigal Research Institute

Chuluunbileg Batbold

Zaigal Research Institute

Saruul Nergui

Zaigal Research Institute

Ron Anderson

Zaigal Research Institute

Alex Heikens

UNICEF MONGOLIA

Moiltmaa Sarantuya

UNICEF

Clarence Wigfall

Claremont Graduate University

David Warburton (D DWarburton@chla.usc.edu )

https://orcid.org/0000-0003-0686-3977

Research

Keywords: Absenteeism, Air pollution, Direct costs, Indirect costs, Private sector

Posted Date: May 28th, 2020

DOl: https://doi.org/10.21203/rs.3.rs-31720/v1

License: (1) This work is licensed under a Creative Commons Attribution 4.0 International License.

Read Full License 


\section{Abstract}

Background Ulaanbaatar, Mongolia, the coldest national capital city, has the highest winter seasonal mean concentrations of $\mathrm{PM}_{2.5}$ and $\mathrm{PM}_{10}$. During January, the coldest month, peak pollution levels are $>8$ times higher than the World Health Organization (WHO) guideline values are reached, on average, 15.7 times. Over $80 \%$ of this seasonal air pollution is due to domestic heating with coal stoves in large ger residential communities that surround much of the city. This report presents an analysis of the direct and indirect costs of wintertime seasonal air pollution due to the absenteeism of private-sector employees.

Methods Questionnaire data were obtained for 1330 employees working for private sector companies over six economic sectors. To assess employee's direct and indirect costs, healthcare-related costs such as cost per hospitalization, medication, and outpatient visits were calculated using the Cost-of-Illness approach. Non-healthcare costs, such as transportation and food, were also estimated in the study. Individual Indirect costs were calculated with the Human Capital Approach, which estimates the hours of work lost by the person due to disease and then multiplies total lost hours by the hourly wage.

Results Approximately $60 \%$ of employee absences occurred during the coldest and hence most air polluted time of 4 months of the year from November to February. Female employees were proportionately more likely to be absent than their male counterparts. Individual direct healthcare costs attributed to air pollution related-sickness absences totaled $1,005,000 \rrbracket(\$ 361.50)$ per year due to being absent from work an average of 3 days three times during the winter in Ulaanbaatar. The median cost of lost wages for 3 days' absence is $120,000 \otimes(\$ 43.20)$.

Conclusions We conclude that wintertime pollution has a major impact on absenteeism rates among private-sector employees, and therefore, we postulate that this must be a significant driver of opportunity costs, affecting not only corporate bottom lines but also employees.

\section{Background}

Of the national capital cities in the world, Mongolia's capital, Ulaanbaatar, is the coldest during the winter season. Burning coal in domestic heating stoves produces $>80 \%$ of the winter seasonal air pollution. The extreme levels of $\mathrm{PM}_{10}, \mathrm{PM}_{2.5}$, SO2, and $\mathrm{CO}$ measured in the air in Ulaanbaatar are strongly associated with adverse health effects, including respiratory, cardiac, and pregnancy-related morbidities. According to the World Health Organization (WHO) guidelines, the mean values of $\mathrm{PM}_{2.5}\left(\mathrm{PM}_{10}\right)$ should not exceed an annual mean of $20 \mu \mathrm{g} / \mathrm{m} 3$ or a 24 -hour mean of $25 \mu \mathrm{g} / \mathrm{m} 3$. Ulaanbaatar is among the global capital cities with the highest seasonally-polluted mean concentration of $\mathrm{PM}_{2.5}$ and $\mathrm{PM}_{10}$, reaching $157 \mu \mathrm{g} / \mathrm{m} 3$. Burning coal in domestic heating stoves produces $>80 \%$ of the winter seasonal air pollution. The extreme levels of $\mathrm{PM}_{10}, \mathrm{PM}_{2.5}, \mathrm{SO}$, and $\mathrm{CO}$ measured in the air in Ulaanbaatar are strongly associated with adverse health effects including respiratory, cardiac and pregnancy-related morbidities. According to the World Health Organization (WHO) guidelines, mean values of $\mathrm{PM}_{2.5}\left(\mathrm{PM}_{10}\right)$ should not exceed an annual mean of $20 \mu \mathrm{g} / \mathrm{m} 3$ or a 24 -hour mean of $25 \mu \mathrm{g} / \mathrm{m} 3$. Ulaanbaatar is among the global capital cities with 
the highest seasonally-polluted mean concentration of $\mathrm{PM}_{2.5}$ and $\mathrm{PM}_{10}$, reaching $157 \mu \mathrm{g} / \mathrm{m} 3$ and $160 \mu \mathrm{g} / \mathrm{m} 3$, respectively, during the winter months.

At a recent UNICEF meeting on air pollution health effects in children, it was postulated that there might be an equally strong association between wintertime air pollution and absenteeism of a child's primary caretaker, which may result in significant opportunity cost to employees.

Absenteeism has been defined as a withdrawal behavior due to an unwanted working environment (Nielsen, 2008). The three main categories of absence are sick leave, authorized absence, and unauthorized absence. Involuntary absence may be distinguished from voluntary absence on the basis that involuntary absence is caused by certified sickness or funeral attendance and is beyond the employee's direct control. In contrast, voluntary absence is associated with uncertified sickness and shirking (Dew et al., 2005). In the US service sector, about 2.3\% of all scheduled working hours are lost because of unplanned absences. However, in other industries, the total cost of unplanned absences may amount to $20 \%$ of payroll expenses.

Every organization has its own human resource management policies. For instance, one employer allows up to five days of paid leave if the employee's wife, husband, parents, children, siblings, grandparents, or parents-in-law have passed away, if the employee is getting married, or the employee's wife has given birth. Also, employees are entitled to take up to four hours of paid leave once a quarter for medical examination (Work time management, 2015).

In Oslo, Norway, an increase in $\mathrm{PM}_{10}$ by $1 \mu \mathrm{g} / \mathrm{m}^{3}$ was associated with a $0.6 \%$ increase in the number of sick-leaves. In addition to the loss of sense of overall well-being (decline in the individual utility of being) and increased financial costs through more utilization of public health services, the Norwegian results indicate that air pollution also entails costs to trade and industry through the higher number of sickleaves (Hansen \& Selte, 2000). An evaluation of sick leave among employees of a large Massachusetts manufacturer found a consistent relation between increased sick leave and lower levels of ventilation (Milton, n.d.). In a study of economic cost assessment of the health effects related to air pollutants in Mumbai and Delhi, the total financial cost attributed to $\mathrm{PM}_{10}$ pollution was, on average, about $1.01 \%$ of India's GDP, from 1991 to 2015, when the GDP growth rate was approximately 5.87\% (Maji et al., 2016).

Employer direct costs include lost paid absence days, sick pay, lost productivity, and reduced service provision, while indirect costs include disruptions, management's time to revise work schedules, administrative costs to monitor and administer the leave policy, loss of expertise and experience, training costs for replacement workers, resentment and lowered morale of other employees, reduced productivity, staff turnover, terminations of contracts, and loss of income (Hoeijenbos et al., 2005). The purpose of our study was to determine the direct and indirect costs of wintertime seasonal air pollution due to the absenteeism of private-sector employees living in Ulaanbaatar, Mongolia.

\section{Methods}




\section{Study setting}

Using a purposive sampling method, we defined target private-sector employers. Inclusion criteria encompassed business type, employee numbers, and willingness to participate in the study.

\section{Data Collection Mixed Methods}

Socio-demographic information of the study participants was collected by questionnaire. Absence information was assessed using five main questions through the questionnaire, such as, have you ever been absent due to sickness during air polluted wintertime? Additionally, absence disaggregation was accomplished using employee demographic information and risk factor assessment associated with absenteeism for the study participants. Absenteeism causes and disaggregation were analyzed through questionnaires and individual employee interviews. Company coping mechanisms linked with absenteeism were assessed through qualitative analysis.

Company absenteeism flexible arrangements were assessed both from the employee and employer perspectives. From the employer side, we used semi-structured face-to-face interviews with human resource managers among selected companies to assess company compensation mechanisms associated with absenteeism. The employee side was assessed through a questionnaire and focus group interviews on understanding company flexible working conditions and any stress related to getting approval from employers due related to sickness associated with wintertime air pollution.

\section{Direct And Indirect Cost Estimation}

To assess employee's direct and indirect costs, healthcare-related costs such as cost per hospitalization, medication, and outpatient visits were calculated using the Cost-of-IIIness approach. Non-healthcare costs, such as transportation and food, were also estimated in the study. Individual Indirect costs were calculated with the Human Capital Approach, which estimates the hours of work lost by the person due to disease and then multiplies total lost hours by the hourly wage.

\section{Statistical analysis}

The categorical quantitative data were summarized by number and percentage. Chi-Square was calculated to compare the absent-from-work and present-at-work groups regarding demographic factors. Binary logistic regression with absence from or presence at work as the dependent variable was used to determine possible risk factors of absenteeism such as age, gender, number of children, and other employee risk factors. The individual direct costs data had a nonparametric distribution that we expressed as median and interquartile range as well as the $95 \%$ Confidence Interval. For qualitative analysis, we identified the categories and sub-categories of interest and wrote brief paragraphs 
summarizing the findings for each sub-category, noting similarities and differences observed across groups.

\section{Results}


Table 1

Socio-demographic characteristics of study participants

\begin{tabular}{|c|c|c|}
\hline Variables & $\mathbf{N}$ & $\%$ \\
\hline \multicolumn{3}{|c|}{ Study employee number by service type ${ }^{a}$} \\
\hline Service sector employee & 248 & 18.7 \\
\hline Manufacturing sector employee & 257 & 19.3 \\
\hline Repair sector employee & 182 & 13.7 \\
\hline Financial sector employee & 521 & 39.2 \\
\hline Sales sector employee & 61 & 4.6 \\
\hline Professional sector employee & 59 & 4.4 \\
\hline \multicolumn{3}{|l|}{ Gender } \\
\hline Male & 653 & 50.0 \\
\hline Female & 653 & 50.0 \\
\hline Age (years, mean \pm sd) & \multicolumn{2}{|c|}{$31.0 \pm 8.0$} \\
\hline \multicolumn{3}{|l|}{ District where they live } \\
\hline Bayanzurkh & 368 & 27.4 \\
\hline Bayangol & 258 & 19.4 \\
\hline Songinokhairkhan & 344 & 25.9 \\
\hline Khan uul & 175 & 13.2 \\
\hline Others & 184 & 13.9 \\
\hline \multicolumn{3}{|l|}{ Education status } \\
\hline University graduate & 1013 & 78.8 \\
\hline High school graduate & 267 & 20.8 \\
\hline Did not graduate & 5 & 0.4 \\
\hline \multicolumn{3}{|l|}{ Average per monthly salary ${ }^{b}(\mathbb{Z})$} \\
\hline$\leq 320,000$ & 65 & 4.9 \\
\hline $320,001-500,000$ & 490 & 36.8 \\
\hline $500,001-900,000$ & 323 & 24.3 \\
\hline
\end{tabular}

a,b obtained from National Statistical Office 1212.mn 


\begin{tabular}{|lll|}
\hline Variables & N & $\%$ \\
\hline $900,001-1300,000$ & 215 & 16.2 \\
\hline $1300,001-1500,000$ & 118 & 8.9 \\
$\geq 1500,001$ & 119 & 8.8 \\
\hline Children & & \\
\hline Yes & 1075 & 80.8 \\
\hline No & 255 & 19.2 \\
\hline Number of children (mean \pm sd) & $2 \pm 1$ & \\
\hline a,b obtained from National Statistical Office $1212 . m n$ \\
\hline
\end{tabular}

Employee demographic characteristics are shown in Table 1. Employees were distributed across six private business sectors. Their Median age was 31 years, and half were female. Their domiciles were distributed across 4 Khoroos (administrative districts) in Ulaanbaatar. Nearly $80 \%$ of employees had received higher education. Their median salary was around 500,000区 (\$185) per month, while $80 \%$ of employees had two children at home(Table 1). Figure 1 shows the proportion of employees who took at least one absence during the last winter (58\%) based on the survey results(Fig. 1). Figure 2 shows the main reasons given by employees to justify absences from work including a doctor visit because of being sick (54\%), as well as taking care of sick children (45\%). Importantly, death in the family was also given as a justification by $27 \%$ (Fig. 2). Employee qualitative results also showed that child sickness was the most common reason given to take a day leave. Illness occurred at least one to three times in a wintertime, and the frequency of feeling sick increased during winter. Regarding employee self-illness questions, rather than asking for sick absence, the employee continued their job at the workplace unless they found themselves very ill, that could not get out of the bed. However, the employees took several hours or the entire day to visit a doctor. "The frequency of sickness had a direct relation with the number of children in a family" as stated by interviewees. Child sickness was frequent and more frequent than employees themselves. Interviewees believed there were various reasons such as the air pollution is more toxic for a child, too many children in the classroom (kindergarten and school) decreases children's immunity, and coughing at the school can easily transmit infections among children. Children up to 3 years of age were more frequently sick during the wintertime, which caused their parents to miss work. Female workers took more time off from work than male workers when their children became sick. Male workers usually took time off for the first 1 or 2 days of a child's sickness, supporting mother and child with the transportation to the health facility and then the men would go back to work, whereas female workers would remain with their sick child if they could not find someone to look after their child.

From the Human Resource managers' perspective, the reasons for being absent from work can be divided into 2 groups: 1) related to sickness, and 2) not related to sickness. Sickness-related absence, especially 
child sickness, was reported more frequently than the illness of other family members to HR managers by employees.

Table 2

Study participant role and flexible management

\begin{tabular}{|c|c|c|}
\hline Questions & $\mathbf{N}$ & $\%$ \\
\hline \multicolumn{3}{|c|}{$\begin{array}{l}\text { How often do you coordinate the duty of co-workers when they are sick during the high air pollution } \\
\text { period? }\end{array}$} \\
\hline Mostly & 144 & 13.4 \\
\hline Sometimes & 276 & 25.7 \\
\hline Rarely & 333 & 31.1 \\
\hline Never & 319 & 29.8 \\
\hline \multicolumn{3}{|c|}{ If yes, have you ever been stressed due to assuming an unplanned missing person's role at your job? } \\
\hline Mostly & 156 & 13.9 \\
\hline Sometimes & 261 & 23.2 \\
\hline Rarely & 296 & 26.3 \\
\hline Never & 412 & 36.6 \\
\hline \multicolumn{3}{|c|}{$\begin{array}{l}\text { Feeling when you request sudden leave from your job due to sickness during high air pollution (single } \\
\text { response) }\end{array}$} \\
\hline Worried & 299 & 26.0 \\
\hline Scared & 599 & 52.1 \\
\hline Relaxed & 193 & 16.8 \\
\hline Other & 58 & 5.0 \\
\hline \multicolumn{3}{|c|}{ Does your company have flexible working arrangements such as working from home or duty sharing } \\
\hline Mostly & 113 & 11.0 \\
\hline Sometimes & 143 & 13.9 \\
\hline Rarely & 146 & 14.2 \\
\hline Never & 625 & 60.9 \\
\hline
\end{tabular}

Table 2 quantifies company policies and employee perceptions of company flexible care policies for sickness-related absences. Almost forty percent of the private company employees that participated in this study had experience coordinating duties of co-workers when they are out sick during the winter air pollution period. The same percentage of employees reported being stressed due to the extra work when others are unexpectedly absent. Eighty percent of study participants in the private sector reported mixed 
feelings of frustration and fear when they ask sick leave during wintertime. Seventy-five percent of the participants revealed no or less flexible time arrangements from their employer(Table 2). Figure 3 showed that sick leave was approved in about a third of employees who asked for it. Nearly half of employees did not receive sick pay, while a small proportion had the option of using sick time or vacation leave(Fig. 3). Almost all workers subtracted their absent days from their vacation or they tried to schedule their vacation in the wintertime when child sickness is frequent. If the sickness-related absence was not taken from their vacation, they sometimes incurred an unpaid absence, unless they bring a sick note from their physician. Unfortunately, some employees did not know about their company's paid absence policy.

Unpaid day leave was most likely when the health provider did not provide a sick note to the employee for the care of children under three years of age, and when the employee used all their vacation time caring for their sick children. In some cases, if there was a lack of a workforce replacement, the employee was obligated to care for their children during the day and work at night or work overtime to accomplish their work. Additionally, from the employee perspective, a sick employee rarely took time off unless they were severely ill. But when their child became sick, the company usually offered no paid sick leave to workers. However, that changed in 2017, when Resolution No. 215 from the Mongolian Government granted paid sick leave for parents taking care of their sick children under age 5. Employees typically tried to find someone, often their parents, or hire somebody to care for their child. If they could not find childcare, the worker took leave from their work using vacation days. For workers who received a health consultation from a public healthcare facility, this was paid by their health insurance. But the majority had to consult with private clinicians incurring out-of-pocket payment, due to some difficulties getting access to timely care in public facilities, when they or their children became ill. Few companies offered private health insurance. 
Table 3

Study participants air pollution exposure assessment

\begin{tabular}{|c|c|c|}
\hline VARIABLES & $\mathbf{N}$ & $\%$ \\
\hline \multicolumn{3}{|l|}{ Smoking status } \\
\hline Yes & 378 & 28.4 \\
\hline No & 952 & 71.6 \\
\hline How many years smoke (mean $\pm S D$ ) & $7 \pm 4$ & \\
\hline \multicolumn{3}{|l|}{ Type of house } \\
\hline Ger & 160 & 12.0 \\
\hline Ger district house & 222 & 16.7 \\
\hline Apartment & 894 & 67.2 \\
\hline Others & 54 & 4.4 \\
\hline \multicolumn{3}{|l|}{ Heating source } \\
\hline Central heating system & 856 & 64.4 \\
\hline Improved fuel & 58 & 4.4 \\
\hline Electrical heater & 254 & 19.1 \\
\hline Wood & 61 & 4.6 \\
\hline Others & 101 & 7.6 \\
\hline \multicolumn{3}{|l|}{ Transportation used to reach work place } \\
\hline Walk & 294 & 22.1 \\
\hline Bicycle & 3 & 0.2 \\
\hline Car & 422 & 31.8 \\
\hline Bus & 608 & 45.7 \\
\hline Company provided transportation & 3 & 0.2 \\
\hline \multicolumn{3}{|c|}{ Season when the air pollution symptoms were experienced the most } \\
\hline Winter & 948 & 71.3 \\
\hline Spring & 307 & 23.1 \\
\hline Autumn & 48 & 3.6 \\
\hline Summer & 27 & 2.0 \\
\hline In your opinion, does air pollution cau & & \\
\hline
\end{tabular}




\begin{tabular}{|lll|}
\hline VARIABLES & N & $\%$ \\
\hline Yes & 1291 & 97.1 \\
\hline No & 39 & 2.9 \\
\hline Born in Ulaanbaatar & & \\
Yes & 537 & 40.4 \\
\hline No & 793 & 59.6 \\
Years lived in ulaanbaatar city & $19.3 \pm 11.0$ \\
\hline Years worked for current employer (mean \pm SD) & \multicolumn{2}{|l|}{$6.4 \pm 3.4$} \\
\hline
\end{tabular}

Table 3 shows an assessment of risk factors for air pollution exposure among employees who participated in this questionnaire study. Twenty-eight percent reported smoking, $67 \%$ lived in apartments, while $29 \%$ lived in ger districts. The $64 \%$ who reported using central heating are presumably those who lived in apartments. Their mean commuting distance is $7 \mathrm{Km}$ (Table 3). Figure 4 shows that the adoption of individual protection methods against air pollution such as mask wearing or air purifiers at home was self-reported by employees to be less than 10\%(Fig. 4). Except for a few participants, the qualitative results revealed that some people report using protection when they go outside, either with an air pollution mask or just with a scarf (which offers no real protection). However, the use of the mask can pose various challenges, for example difficulty, difficulty breathing and eyeglasse fogging (the latter means the mask doesn't properly fit and thus provides little to no protection). Air pollution mask usage seemed to depend on location, for example, Residents from Bayankhoshuu districts (highly polluted region) were more likely to use air pollution mask in wintertime. Nearly all respondents providing a mask to their children in wintertime, some schools and parents require students to use a mask, even though its was uncomfortable to use, while other families were not sure whether their children used the mask regularly or not despite their parents' expense and effort. As a protective measure, the air pollution face mask typically costs between 1600 to $5000 \otimes(\$ 0.60$ - \$1.80) per week and men usually buy the mask for their children and wife rather than for themselves. Moreover, employees typically purchase an air purifier and replacement filters for their home and/or workplace and pollution filter with their own money. 
Table 4

Workplace absenteeism potential risk factors.

\begin{tabular}{|c|c|c|c|c|c|c|c|c|}
\hline \multirow{3}{*}{$\begin{array}{l}\text { Variables } \\
\text { OR }\end{array}$} & \multicolumn{4}{|c|}{ Crude OR } & \multicolumn{4}{|c|}{ Adjusted OR } \\
\hline & \multicolumn{2}{|c|}{$95 \%, \mathrm{Cl}$} & \multirow[t]{2}{*}{$\mathrm{p}$} & \multirow[t]{2}{*}{ OR } & \multicolumn{2}{|l|}{$95 \%, \mathrm{Cl}$} & \multirow[t]{2}{*}{$P$} & \\
\hline & Lower & Upper & & & Lower & Upper & & \\
\hline \multicolumn{9}{|l|}{ Gender } \\
\hline Male & 1 & & & & 1 & & & \\
\hline Female & 1.65 & 1.29 & 2.11 & 0.00 & 1.63 & 1.04 & 2.54 & 0.03 \\
\hline Age, (Sig). & \multicolumn{8}{|c|}{$0.002(0.319)$} \\
\hline \multicolumn{9}{|l|}{ Having a child at home } \\
\hline Yes & 2.23 & 1.62 & 3.07 & 0.00 & 2.90 & 1.87 & 4.49 & 0.001 \\
\hline No & 1 & & & & 1 & & & \\
\hline \multicolumn{9}{|c|}{ Air pollution-related self-reported diseases } \\
\hline Yes & 1.17 & 0.90 & 1.52 & 0.23 & 3.08 & 0.87 & 10.97 & 0.08 \\
\hline No & 1 & & & & 1 & & & \\
\hline \multicolumn{9}{|c|}{ Company air pollution coping techniques } \\
\hline Yes & 1 & & & & 1 & & & \\
\hline No & 1.64 & 1.10 & 2.44 & 0.01 & 1.46 & 0.91 & 2.36 & 0.19 \\
\hline \multicolumn{9}{|l|}{ Body mass index } \\
\hline Normal weight & 1 & & & & & & & \\
\hline Overweight and obese & 1.10 & 0.94 & 1.45 & 0.09 & 1.12 & 0.98 & 1.65 & 0.12 \\
\hline \multicolumn{9}{|c|}{ Do you use air purifier at home? } \\
\hline Yes & 1 & & & & 1 & & & \\
\hline No & 1.11 & 0.82 & 3.4 & & 1.28 & 0.79 & 4.03 & 0.16 \\
\hline \multicolumn{9}{|c|}{ Are you passive smokers at workplace or home? } \\
\hline Never & 1 & & & & 1 & & & \\
\hline Sometimes & 1.18 & 0.64 & 2.12 & & 1.45 & 0.74 & 2.84 & 279 \\
\hline Mostly & 1.15 & 0.74 & 1.78 & & 1.21 & 0.74 & 1.93 & 0.41 \\
\hline \multicolumn{9}{|c|}{ Years worked at the same company } \\
\hline Sig - Significance, & & & & & & & & \\
\hline
\end{tabular}




\begin{tabular}{|c|c|c|c|c|c|c|c|}
\hline Variables & \multicolumn{3}{|c|}{ Crude OR } & \multicolumn{4}{|c|}{ Adjusted OR } \\
\hline$\leq 5.0$ years & 1 & & & 1 & & & 0.01 \\
\hline$>5.1$ years & 1.36 & 1.05 & 1.75 & 1.39 & 1.11 & 1.62 & \\
\hline
\end{tabular}

Table 4 shows that female gender and having children are significant risk factors for workplace absences during the winter pollution season, whereas self-reported air pollution-related diseases and company air pollution-coping techniques are not. A female was 1.65 times more likely to be absent than her male counterparts. Even after adjustment for other variables, female gender remains a significant factor for air pollution-related workplace $(p=0.03 ; 95 \mathrm{Cl} 1.04-2.54)$. Reporting having a child imparts 1.87 times higher odds of being absent than persons without children adjusted by other factors $(p<0.001 ; 95 \mathrm{Cl}$ 1.87-4.49). Both self-reported diseases and company air pollution coping techniques were 1.17 and 1.64 times more associated with absence. However, these risk factors became non-significant after adjusting for confounders $(p=0.08 ; 95 \mathrm{Cl} 0.87-10.97$ and $p=0.19 ; 95 \mathrm{Cl} 0.91-2.36)$. Being overweight and obese were not associated with being absent compared to the normal BMI group. Lastly, being a passive smoker ( $p=0.41 ; 95 \mathrm{Cl} 0.74-1.93)$ and working for a company greater than five years were significant factors associated with absenteeism $p=0.01 ; 95 \mathrm{Cl} 1.11-1.62$ ) (Table 4).

Table 5

Individual health care and non-health care-related direct costs attributed to wintertime air pollution

$\begin{array}{lll}\text { Cost Frequency } & \begin{array}{l}\text { Median cost per } \\ \text { occurrence }\end{array} & \text { Total cost }\end{array}$

Individual health care-related direct costs

Diagnostic services and doctor visit-related costs

3

65000区

195000区

Medication purchasing-related costs

Hospitalization-related costs

Total individual healthcare-related direct costs

4

1

3

$335000 \mathbb{8}$

70000区

200000区

280000区

200000区

1005000区

\section{Individual non-health care-related direct costs}

Transportation

4

$50000 \rrbracket$

200000区

Q-Symbol for Mongolian tugrik currency

Table 5 shows the contributing components to direct costs to employees for medical-related absences during the wintertime air pollution season. Principal cost drivers include doctor visits for diagnosis and related costs, buying medicine at the pharmacy, hospitalization, if necessary, and transportation to obtain care. The average cost associated with diagnosis and doctor visit was 195,000》 (\$70.10). Four 
medications were typically purchased with an average cost of 280,000 (\$100.70). During last winter, the median number of visits to the doctor was 3 (Table 5). From qualitative analysis among employee participants, most of them reported having a bad experience during their family doctor consultation at a public facility and commented that the physician was usually a recently graduated young woman, who had poor skills and was not perceived as trustworthy; thus the employee was not satisfied with the service. Furthermore, the treatment received was not effective, so they had to consult with a private doctor later. Some mentioned that everything depended on how the family doctor managed the illness from the start. Participants also commented that doctors were usually uncertain about the cause of the sickness and often transferred patients from doctor one to another, which was costly and time-consuming for participants. Another reason for seeking care at private healthcare facilities was the long delay for patients at the public healthcare facilities, often months, and that the family often felt they could not wait for their child sick to be seen. Some private healthcare facilities offered free second opinions within 14 days of being evaluated at a public facility, while others charged for 20000区 (\$7.20). Importantly, private healthcare facilities offered consultation on the weekends, which allowed the employee to see the doctor without missing work. One employee reported having a private medical concierge consultant, which cost 80000》 (\$28.80) per month.

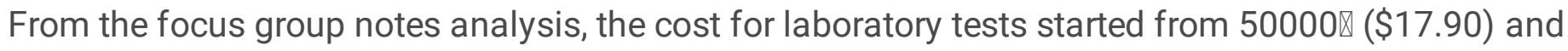
reached a maximum of $200000 \otimes$ ( $\$ 71.90)$. For radiology tests, the cost varied between $15000 \otimes(\$ 5.40)$ to $300000 \otimes(\$ 107.90)$ and some health providers, who work at public healthcare facilities, requested that the $\mathrm{X}$-ray be done at private facilities.

When the employee or their child becomes ill, they try to resolve it as soon as possible, so they purchase oral or IV antibiotics over-the-counter at a pharmacy, without medical consultation, while having vitamins, seabuckthorn or lingonberry juices, and fermented hot, dry milk at home. Believing it led to a fast recovery, high dose antibiotics were often misused to treat viral illnesses compounding the problem of antibiotic resistance. Participants also mentioned changing their medicine on the third or seventh day after initial treatment, if they do not see any health improvement, leading them to buy other medication and waste the previous ones.

Participants spend money not only for medication but also to support their children's and their own immune system with vitamin C, D, and influenza vaccination. For vitamin C, they may spend 30,0008 (\$10.80) to 300,000区 (\$107.90) per month depending on the number of users, while for vitamin D 60,000区 (\$21.60) monthly for two children. The main medications used for sickness were self-prescribed antibiotics and others, namely painkillers, probiotics, anti-allergy medications, medicine for fever, and nebulization or inhalation. Some participants also responded that they were willing to buy the most expensive and what they perceived to be the most effective drugs for fast recovery. Furthermore, many reported that recovery from illness might take more than a month, and some have an incomplete recovery and become ill again. Overall, they believed that recovery depends on the density of children in the stateowned kindergarten, the family doctor skills, and access to medical service. Participants also responded to use multiple antibiotics in higher doses just for perceived faster recovery. The cost was between 
30,000-500,000区 (\$10.80 - \$179.80) per illness, 20,000-25,000区 per single medication, 20,000-400,000区 (\$7.20 - \$143.90) per child, 30,000-200,000区 (\$10.80 - \$71.90) per adult, 9000》 (\$3.20) per day, 2800》$7,000 \otimes(\$ 1.00$ - $\$ 2.50)$ per capsule or tablet of medicine, 5000冈 (\$1.80) for nebulization and all those multiply with sickness repetition, number of medications used, number of children in a family, duration of treatment (typically 3-7 days) and frequency of medicine taken in one day (usually 3 times per day). Different aged children used different forms of the same medicine, such as capsule, syrup, or nebulization, with different prices. Medicine for children under the age of three was the most expensive according to their experience. If they requested that an injection be administered at home, a payment of $5000 \otimes(\$ 1.80)$ added for each daytime call for the on-call nurse. When modern medicine was not effective in two months, phytotherapy, traditional therapy, or immune-based treatment was tried. Most of the participants did not have insurance coverage to buy medicine, lacked knowledge regarding which medicine to buy, and often found a lack of medicine available in the pharmacy. Self-medication was frequent. Participants knew that pharmacists were not trained to be clinicians, yet they still tended to go to the pharmacy and consult with them and bought the medicine they recommended. For air pollution, some people received hyperbaric oxygen and treatments using oxygen concentrators, which costed $50,000 \rrbracket$ (\$17.90) per person. Rezine (cetirizine), an anti-allergy medication, was the most commonly used drug in the summer.

Many respondents commented that pharmaceutical companies often promoted their expensive medicines to the physicians and pharmacists, who then sold them at high prices to the employee. On the other hand, some employees complained that family doctors always prescribed only vitamin $\mathrm{C}$ and Amoxicillin.

Hospitalization-related cost per occurrence was 200,000 (\$71.90). Total healthcare-related average direct cost was estimated to be $1,005,000 \otimes(\$ 361.50)$ per year. The individual non-healthcare-related cost was estimated to be $200,000 \otimes(\$ 71.90)$ per year. Per person direct cost, including medical and non-medical costs, totaled to an average $1,205,000 \mathbb{Q}(\$ 433.40$ ) per employee who took a sickness-related absence last winter. The qualitative analysis demonstrated that access to care at the public healthcare facilities was difficult, and was perceived to be risky because of misdiagnosis and complications and that complicated cases often required hospitalization. Due to the scarce availability of public hospital beds, most participants went to private hospitals; however, there were still some people whose children were hospitalized in public facilities. Private rooms in the state hospitals were also available at an additional cost, which varies between $25,000-35,000 \mathbb{Q}(\$ 8.90$ - $\$ 12.60)$ per hospitalization. Simultaneous hospitalization of more than one child in the public hospitals was logistically more difficult for the employees, which is another reason why most of them preferred private hospitals. The private hospital bed fee per day ranged between 100,000区 (\$35.60) and 150,000》 (\$53.90). Treating pneumonia in the

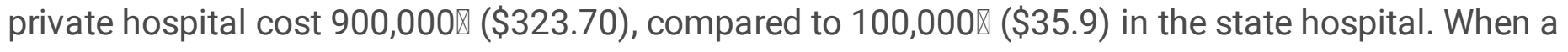
family member was hospitalized, a transportation cost was incurred, whether by bus, taxi, or fuel.

Mongolia's Social Health Insurance Agency selects "essential drugs" annually and sets the maximum price for these drugs as well as the extent to which the government will reimburse their cost. Employees

Page 15/24 
noted that most physicians neither guided their patients to use insurance nor prescribed medication from the list of essential drugs subsidized by the government. Respondents said that having insurance coverage for essential medicines was good. Still, the quantity ordered by the pharmacies was not enough so that once the medication was on the essential drug list, it ran out immediately after which there was a long queue for it. For young people aged between 25-34 there were no insurance benefits. Most of the participants interviewed had not benefited from insurance because there was no insurance coverage for coughing due to air pollution.

Table 6

Individual indirect cost using human capital approach

\begin{tabular}{|c|c|c|c|c|c|}
\hline \multirow[b]{2}{*}{ Variables } & \multirow[b]{2}{*}{ Median } & \multicolumn{2}{|c|}{$95.0 \%, \mathrm{Cl}$} & \multicolumn{2}{|c|}{ Interquartile } \\
\hline & & Lower & Upper & 25th & 75th \\
\hline Number of days absent & 3 & 3 & 5 & 2 & 7 \\
\hline 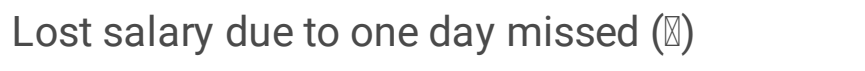 & 35000 & 30000 & 40000 & 25000 & 50000 \\
\hline Individual indirect cost due to absenteeism (区) & 120000 & 80000 & 210000 & 60000 & 245000 \\
\hline
\end{tabular}

Table 6 described the effect of absenteeism on human capital costs. This calculation revealed the substantial increases in human capital costs that were driven by increases in days of absence. The median indirect cost due to three missed days of work was $120,000 \otimes(\$ 43.20)$ in this study $(95 \% \mathrm{Cl}$ $80,000-210,000 \rrbracket)$. One missed day cost 35,000区 (\$12.60).

\section{Discussion}

The main findings of our study relate to employee absenteeism due to reported genuine illness and its costs. Illness-related work absence is very costly to employers who offer sick leave because employees are paid for time when they are not working. It is likewise very costly to employees without sick leave due to lost wages. Regardless of sick leave coverage, it always is associated with work being not accomplished, delayed, or shifted to others and is associated with increased healthcare expenses care.

Sick leave is a right afforded to employees, which allows them to recover from illness (Mostert, 2010). Yet sick leave often spills over to absenteeism related to providing care to other ill family members. Childcare is often a serious cost issue, as revealed by our study. Another common family problem is the responsibility of adult children to care for their elderly parents. These needs may include doctor/medical appointments and hospitalizations, all of which take time and money to complete (Kocakulah \& Kelley, 2016).

Our study showed higher rates of absences reported by female employees with young children. The number of children in the household also had a significant impact on work-place absenteeism in this 
study. Women take more responsibility for children and are therefore, more often absent, particularly as the number of young children in the family increases (Leigh, 1983).

The weaknesses in our study include the possibility of recall bias in focus group interviews, socioeconomic selection bias because the subjects were all employed persons, and thus possible overestimation of the potential out of pocket GDP impact on employees in the general population. Representativeness of the study was limited by the purposive sampling method. We studied the direct and indirect costs associated with absenteeism, which our study participants attributed to air pollution. We did not identify the extent to which confounding variables, such as wintertime respiratory infections, affected these costs. Separating the effects of air pollution from infection would require determining absenteeism associated with personal air pollution exposure or differences in air pollution exposure among smaller groups of people at ground level in the same wintertime conditions. Interpreting the results would then require determining how much air pollution impacts the direct and indirect costs of seasonal respiratory infections.

The evaluation of measures affecting air quality management both at the individual, company, and societal levels needs to account for the impacts of pollution on public health, as well as the effectiveness, benefits, and costs of the measures to reduce pollution. Accordingly, air pollution exposure assessment is a necessary element of the health risk assessment. For many air pollutants, no risk-free exposure threshold values have been defined. This means that it is likely that at all levels of exposures, there are individuals for whom exposure reductions would bring health benefits. Therefore, the entire exposure distribution is relevant for the population-level risk assessment, not only when air pollution exceeds a particulate exposure level. This information is needed for the general population as well as for population subgroups of particular interest.

\section{Conclusion}

We conclude that the identified combined direct and indirect costs of absenteeism attributed to wintertime air pollution in Ulaanbaatar, Mongolia are compelling. The major identified drivers of direct cost to employees are healthcare expenses, including doctor visits, medication, hospitalization, transportation, plus the cost of loss of earnings. Although employees were equally divided by gender, the cost of sick absences falls disproportionately on female workers with young children. The major cost drivers to employers are the number and human capital cost of employee absences. Clearly, the level of economic opportunity cost analyzed herein is not sustainable and negatively affects the growth of the GDP of Mongolia. Further econometric research is needed to contrast the ongoing opportunity cost of air pollution due to domestic coal-burning versus the cost of investment in remediation and sustainable energy such as solar and wind power.

\section{Abbreviations}

WHO 
World Health Organization, UNICEF:United Nations Children's Fund, US:United States, IV:Intravenous, GDP:Gross Domestic Product.

\section{Declarations}

\section{Ethics approval and consent to participate}

Ethical approval was given by the Mongolian National University of Medical Sciences (\#2019/03-13) and written and verbal informed consent was obtained from each participant.

\section{Consent for publication}

Not applicable.

\section{Availability of data and materials}

The datasets used and/or analysed for the current study are available from the corresponding author on reasonable request.

\section{Competing interests}

The authors declare that there is no conflict of interest.

\section{Funding}

We thank for the The Swiss Agency for Development and Cooperation and the United Nations Children's Fund are co-financing organizations for this study.

\section{Authors' contributions}

MG concepted and wrote the manuscript. DW, RA and CW added essential materials for interpretation and revised the manuscript. NE analysed and wrote interpretation quantitative data of this study. NA revised and added essential interpretations for quantitative analysis section. SN and CB did qualitative analysis and wrote this section. AH and MS participated in data collection, validation and manuscript preparation. The authors read and approved the final manuscript.

\section{Acknowledgments}

We thank the Swiss Agency for Development and Cooperation to co-financing this study. Our sincere gratitude to UNICEF's chief of Social Policy, Enkhnasan Nasan-Ulzii, for practical support throughout the implementation. We thank all the employers and employees for sharing their data and insights that made this study possible.

\section{References}


1. Allen SG. TRADE UNIONS, ABSENTEEISM, AND EXIT-VOICE. Industrial Labor Relations. 1984;37:33145.

2. Brouwer WBF, Meerding WJ, Lamers LM, Severens JL. The Relationship between Productivity and Health-Related QOL: An Exploration. PharmacoEconomics. 2005;23(3):209-18. https://doi.org/10.2165/00019053-200523030-00002.

3. Chan K, Jeremy NV, Miles S, Zellmer K, Watkins ME, Larimer, Alan Marlatt G. Addictive Behaviors Exploring Productivity Outcomes from a Brief Intervention for At-Risk Drinking in an Employee Assistance Program. Addict Behav. 2010;35(3):194-200. https://doi.org/10.1016/j.addbeh.2009.10.001.

4. Chang T, Neidell M, Chang T, Joshua GZ. The Effect of Pollution on Worker Productivity: The Effect of Pollution on Worker Productivity : Evidence from Call-Center Workers in China. American Economic Journal. 2016;11(1):151-72.

5. Chang T, Zivin JG, Gross T, and Matthew Neidell. Particulate Pollution and the Productivity of Pear Packers. American Economic Journal. 2016;8(3):141-69.

6. Dew K, Keefe V, Small K. "' Choosing ' to Work When Sick. Workplace Presenteeism". 2005;60:227382. https://doi.org/10.1016/j.socscimed.2004.10.022.

7. Easton FF, John CG. Schedule Recovery: Unplanned Absences in Service Operations. Decision Science. 2005;36(3):459-88.

8. Forbes. 2013. "The Causes And Costs Of Absenteeism In The Workplace." 2013. https://www.forbes.com/sites/deloitte/2019/07/31/a-new-mindset-viewing-cyber-as-an-enabler-ofbusiness-growth-and-innovation-driver/\#2ea1001970a3.

9. Goetzel RZ, Stacey R, Long, Ronald J, Ozminkowski K, Hawkins S, Wang, and Wendy Lynch. Health, Absence, Disability, and Presenteeism Cost Estimates of Certain Physical and Mental Health Conditions Affecting U.S. Employers. J Occup Environ Med. 2004;46(4):398-412. https://doi.org/10.1097/01.jom.0000121151.40413.bd.

10. Gosselin E, Lemyre L, and Wayne Corneil. Presenteeism and Absenteeism: Differentiated Understanding of Related Phenomena. J Occup Health Psychol. 2013;18(1):75-86. https://doi.org/10.1037/a0030932.

11. Hansen AC, Harald K, Selte. Air Pollution and Sick-Leaves: A Case Study Using Air Pollution Data from Oslo. Environmental Resource Economics. 2000;16(1):31-50. https://doi.org/10.1023/A:1008318004154.

12. Hoeijenbos M, Bekkering T, Lamers L, Hendriks E, Van Tulder M, and Marc Koopmanschap. CostEffectiveness of an Active Implementation Strategy for the Dutch Physiotherapy Guideline for Low Back Pain. Health Policy. 2005;75:85-98. https://doi.org/10.1016/j.healthpol.2005.02.008.

13. Kocakulah MC, and Ann Kelley. Absenteeism Problems And Costs: Causes Effects And Cures. International Business Economic Research Journal. 2016;15 15:89-96. https://doi.org/10.19030/iber.v15i3.9673. 
14. Koopmanschap MA, Martin van B, Ineveld. Towards a New Approach for Estimating Indirect Costs of Disease. Soc Sci Med. 1992;34(9):1005-10. https://doi.org/10.1016/0277-9536(92)90131-9.

15. Law on Labour on Mongolia. 1999. Mongolia. https://www.legalinfo.mn/law/details/565.

16. Leigh JP. “Sex Differences in Absenteeism”. 1983;22(3):349-61.

17. Loisel P, Anema JR. 2013. "Handbook of Work Disability: Prevention and Management." In Handbook of Work Disability: Prevention and Management, 1-513. https://doi.org/10.1007/978-1-4614-6214-9.

18. Maji K, Jyoti AK, Dikshit, and Ashok Deshpande. Disability-Adjusted Life Years and Economic Cost Assessment of the Health Effects Related to PM 2. 5 and PM 10 Pollution in Mumbai and Delhi, in India from 1991 to 2015. Environ Sci Pollut Res. 2016. https://doi.org/10.1007/s11356-016-8164-1.

19. Milton DK. Risk of Sick Leave Associated with Outdoor Air Supply Rate, Humidification and Occupant Complains.Pdf. Indoor Air. 2000;10:212-21.

20. Mitchell RJ, Ronald J, Ozminkowski, and Seth Serxner. Improving Employee Productivity Through Improved Health. Occupational Evironmental Medicine. 2013;55(10):1142-48.

https://doi.org/10.1097/JOM.0b013e3182a50037.

21. Mostert K. Work - Home Interference: Examining Socio - Demographic Predictors in the South African Context. SA Journal of Human Resource Management. 2010;8(1):1-10. https://doi.org/10.4102/sajhrm.v8i1.203.

22. National Statistic Office. 2017. "Household Social and Financial Study.".

23. Nielsen AL. Determinants of Absenteeism in Public Organizations: A Unit-Level Analysis of Work Absence in a Large Danish Municipality. The International Journal of Human Resource Management no December. 2008;2014:37-41. https://doi.org/10.1080/09585190802110158.

24. Patel JG, Saurabh P, Nagar, Anand AD. Indirect Costs in Chronic Obstructive Pulmonary Disease: A Review of the Economic Burden on Employers and Individuals in the United States. International Journal of COPD. 2014;9:289-300.

25. 10.4209/aaqr.2011.12.0235

Rodrigues-silva, Fernando UDeP, Santos P, Hilário N, Saldiva, Luis Fernando Amato-lourenço, Simone Georges, and El Khouri. 2012. "Health Risks and Economic Costs of Absenteeism Due to Air Pollution in São Health Risks and Economic Costs of Absenteeism Due to Air Pollution in São." Aerosol and Air Quality Research 12: 826-33. https://doi.org/10.4209/aaqr.2011.12.0235.

26. Schultz AB, Chen CY, Edington DW. The Cost and Impact of Health Conditions on Presenteeism to Employers: A Review of the Literature. PharmacoEconomics. 2009;27(5):365-78.

http://www.embase.com/search/results?

subaction=viewrecord\&from=export\&id=L355010771\%5Cnhttp://dx.doi.org/10.2165/00019053200927050-00002\%5Cnhttp://sfx.metabib.ch/sfx_locater?sid=EMBASE. \&issn=11707690\&id=doi:10.2165\%2F00019053-200927050-00002\&atitle=The+co.. "." ) .

27. Soliman AM, Surrey E, Bonafede M, Nelson JK, and Jane Castelli-Haley. Real-World Evaluation of Direct and Indirect Economic Burden Among Endometriosis Patients in the United States. Advances in Therapy. 2018;35(3):408-23. https://doi.org/10.1007/s12325-018-0667-3. 
28. Soliman AM, Taylor H, Bonafede M, Nelson JK, and Jane Castelli-Haley. Incremental Direct and Indirect Cost Burden Attributed to Endometriosis Surgeries in the United States. Fertil Steril. 2017;107(5):1181-90.e2. https://doi.org/10.1016/j.fertnstert.2017.03.020.

29. Weng SF, Shehzad, Ali, and Jo Leonardi-bee. 2011. "Smoking and Absence from Work: Systematic Review and Meta-Analysis of Occupational Studies," 307-19. https://doi.org/10.1111/add.12015.

30. Wooden M. A Disaggregated Approach to the Study of Absence from Work. Industrial Relations. 1995;22(March):349-61. https://doi.org/10.1080/10301763.1995.10669134.

31. Work Time Management. 2015.

32. Xue S, Zhang B, and Xiaofeng Zhao. Brain Drain: The Impact of Air Pollution on Firm Performance Brain Drain. " no. Mar: The Impact of Air Pollution on Firm Performance; 2019.

\section{Figures}

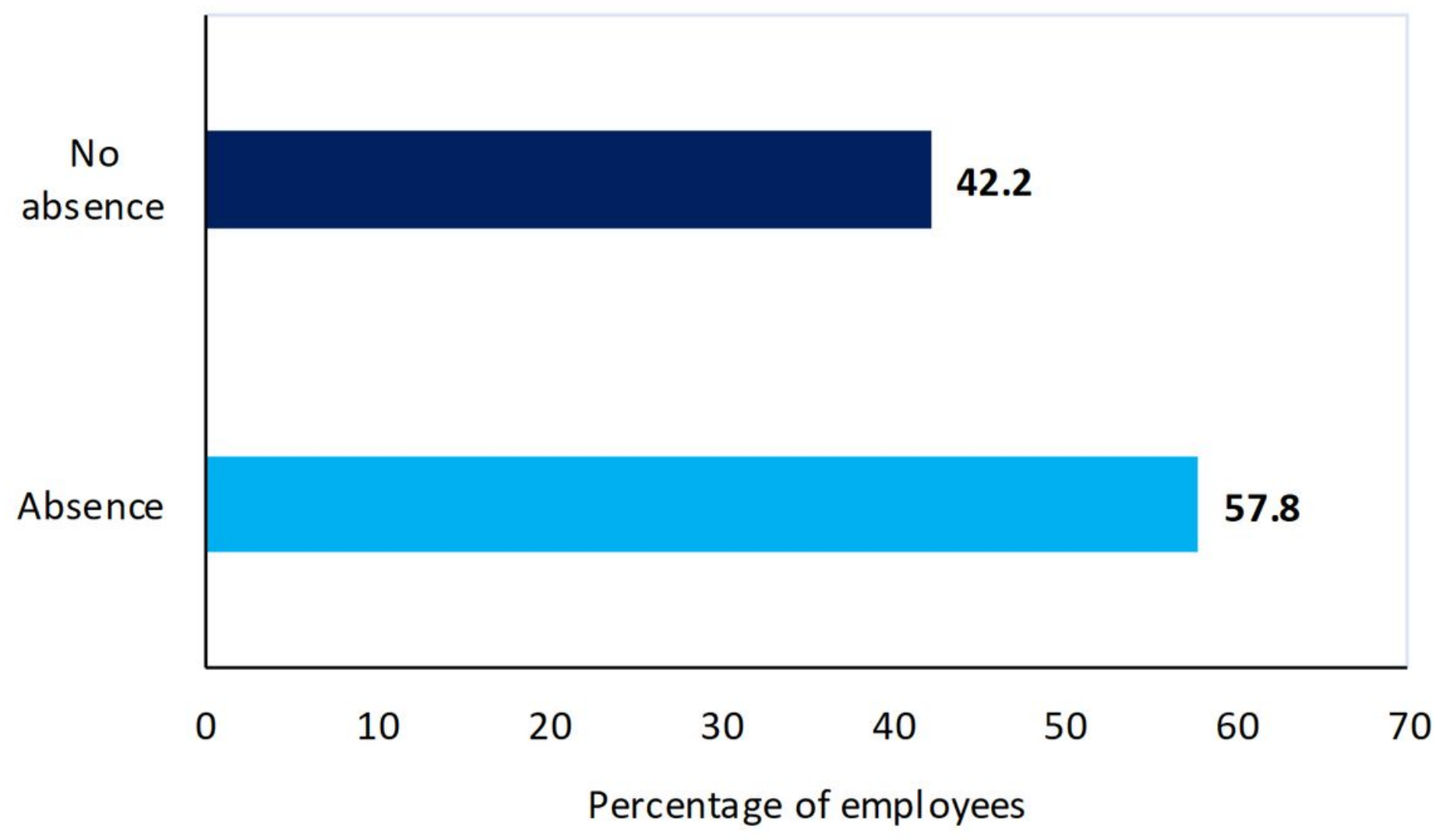

Fig 1. Self-reported wintertime absenteeism rate attributed to wintertime air pollution among study selected participants

\section{Figure 1}

Figure 1 


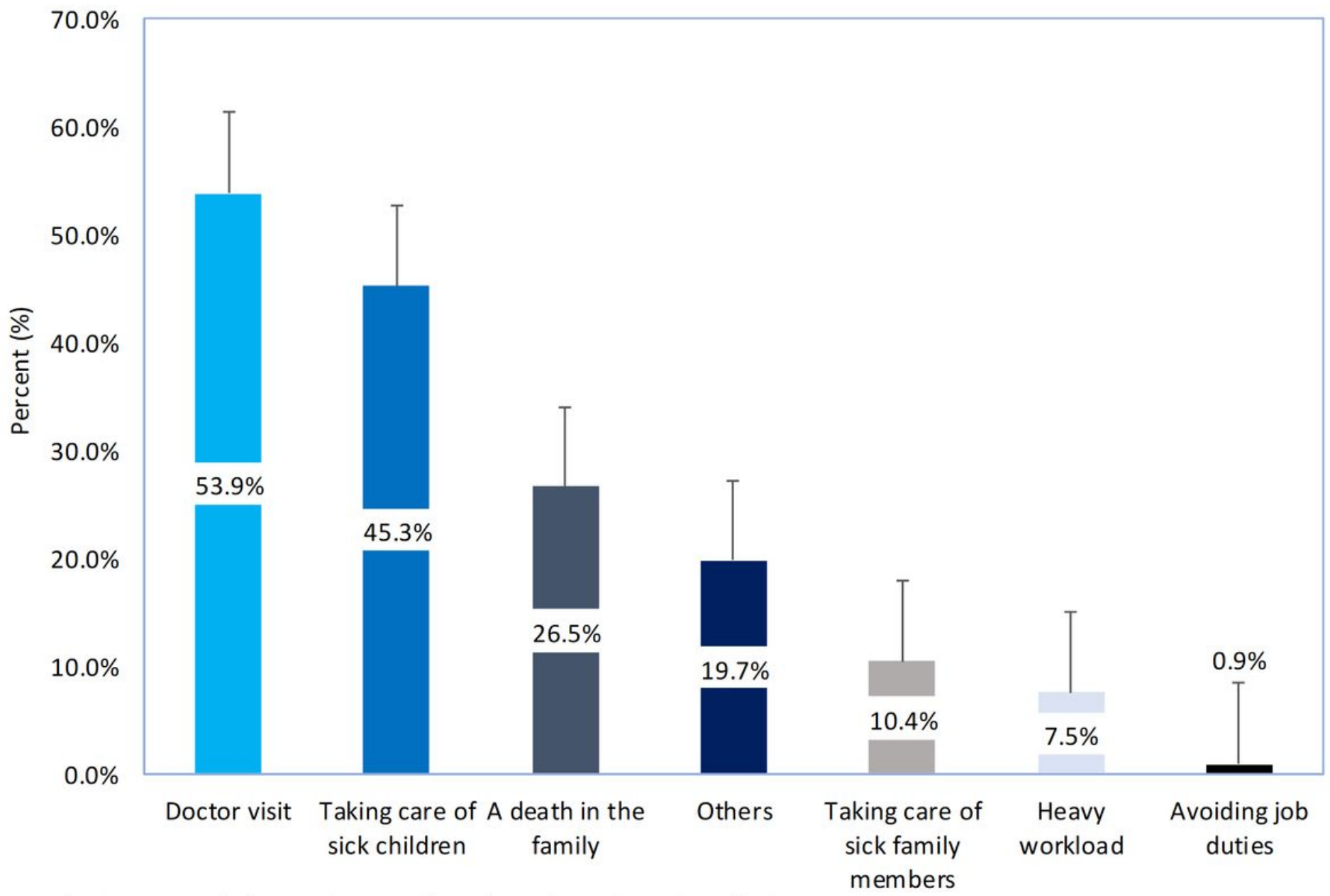

Fig. 2 Causes of absenteeism attributed to wintertime air pollution.

Figure 2

Figure 2 


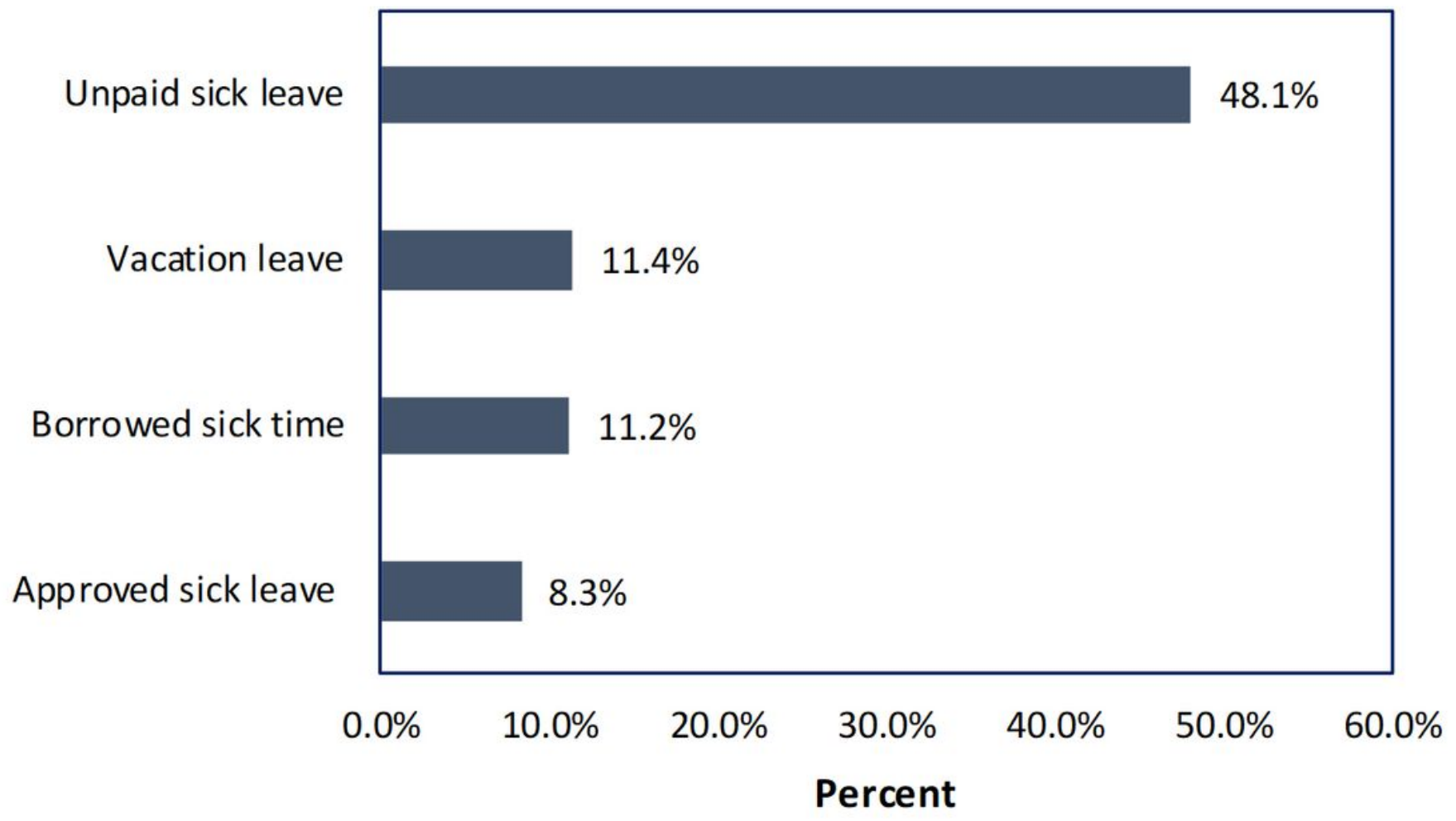

Fig. 3 Types of temporary leave among study participants.

\section{Figure 3}

Figure 3

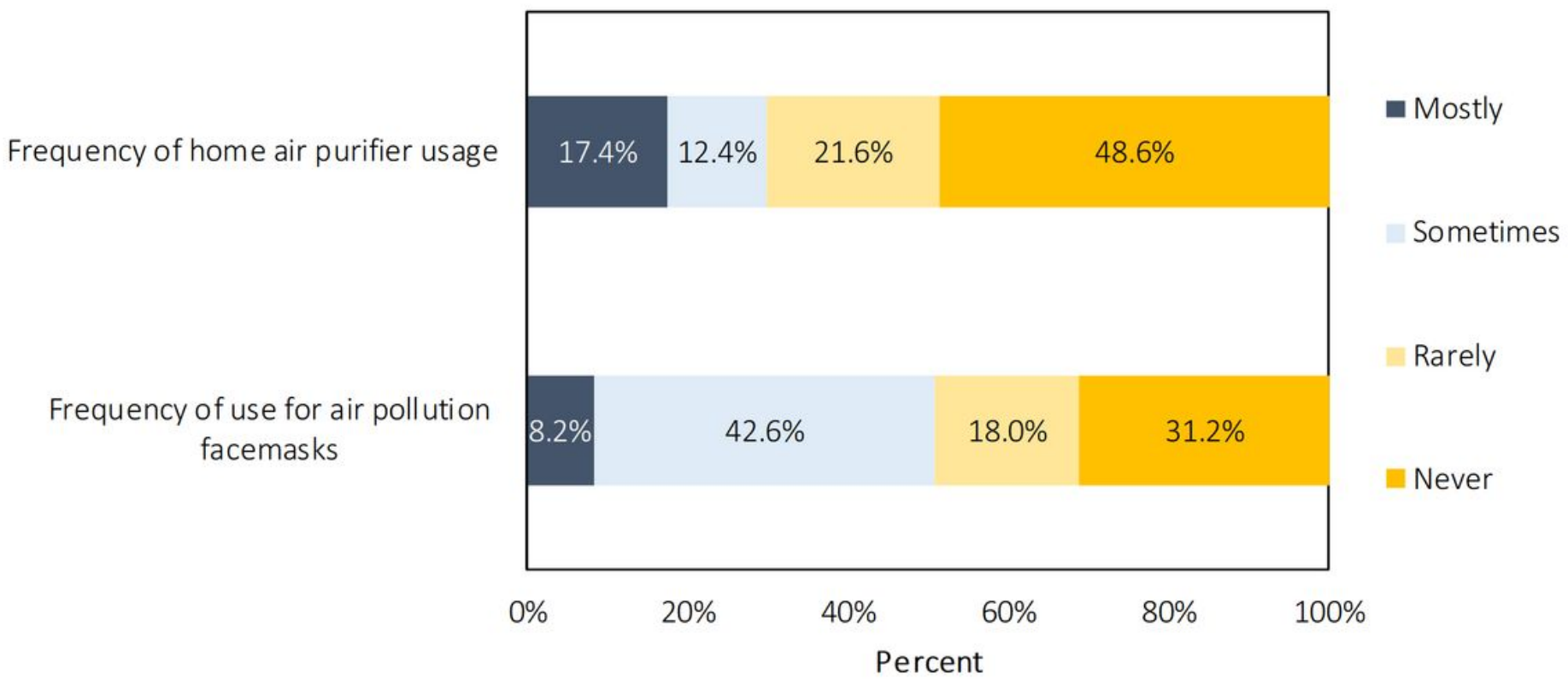

Fig 4. Individual employee air pollution self-protection methods

\section{Figure 4}


Figure 4

Page 24/24 